\title{
KNOWLEDGE AND AWARENESS OF HPV AND HPV VACCINE AMONG HIV POSITIVE WOMEN IN LAGOS, NIGERIA
}

E. A. Sajo ${ }^{1}$, J. Ozonu ${ }^{2}$, K.S. Okunade ${ }^{3}$, J. Ejiofor ${ }^{2}$, M. Adenekan ${ }^{1}$, L.C. Amaeshi ${ }^{4}$, R.I. Anorlu ${ }^{3}$, S. Akanmu ${ }^{5}$.

${ }^{1}$ Lagos University Teaching Hospital, Obstetrics and Gynecology, Lagos, Nigeria.

${ }^{2}$ Lagos University Teaching Hospital, Nursing services, Lagos, Nigeria

${ }^{3}$ University of Lagos College of Medicine, Obstetrics and Gynecology, Lagos, Nigeria.

${ }^{4}$ Lagos University Teaching Hospital, Medicine, Lagos, Nigeria.

${ }^{5}$ University of Lagos College of Medicine, Haematology and Blood Transfusion, Lagos, Nigeria

\section{BACKGROUND}

Human papillomavirus (HPV) infection of the genital tract is one of the most common sexually transmitted diseases (STDs) and subgroup of genital tract HPVs are etiologically associated with anogenital tract cancers

Human immunodeficiency virus (HIV) infected individuals are at higher risk of HPV infection and HPV associated cancers

We determined the knowledge and awareness of HPV infection and HPV vaccine among women living with HIV in Lagos

\section{METHODOLOGY}

A descriptive cross-sectional survey was carried out on 220 HIV positive women who attended the HIV clinic of a tertiary healthcare facility in Lagos from 1st February 2018-31st January 2019. Interviewer administered questionnaire was used to extract information regarding the knowledge of HPV and awareness of HPV vaccine.

Stata Version 13 statistical package was used to analyze the data.

\section{Results}

The mean age of participants was $42.3 \pm 7.6 y e a r s$. This study showed that there is poor knowledge of HPV infection among HIV positive women even though majority $(71.45 \%)$ of the respondents have been living with HIV for over 10 years. The awareness of the protective HPV vaccine was also very low (22.3\% ). Only $37.3 \%$ of the respondents knew HPV could cause cancer with cervical cancer being the most (70\%) identified. 166 (75.6\%) of them didn't know that they were more at risk of having cervical cancer as compared to their HIV negative counterparts. None of the children of the women had been vaccinated against HPV. Only $2.7 \%$ of them knew that the vaccine is given to both boys and girls despite having children living with HIV and were above 10yrs old
Figure 1 Knowledge of HPV infection among participants

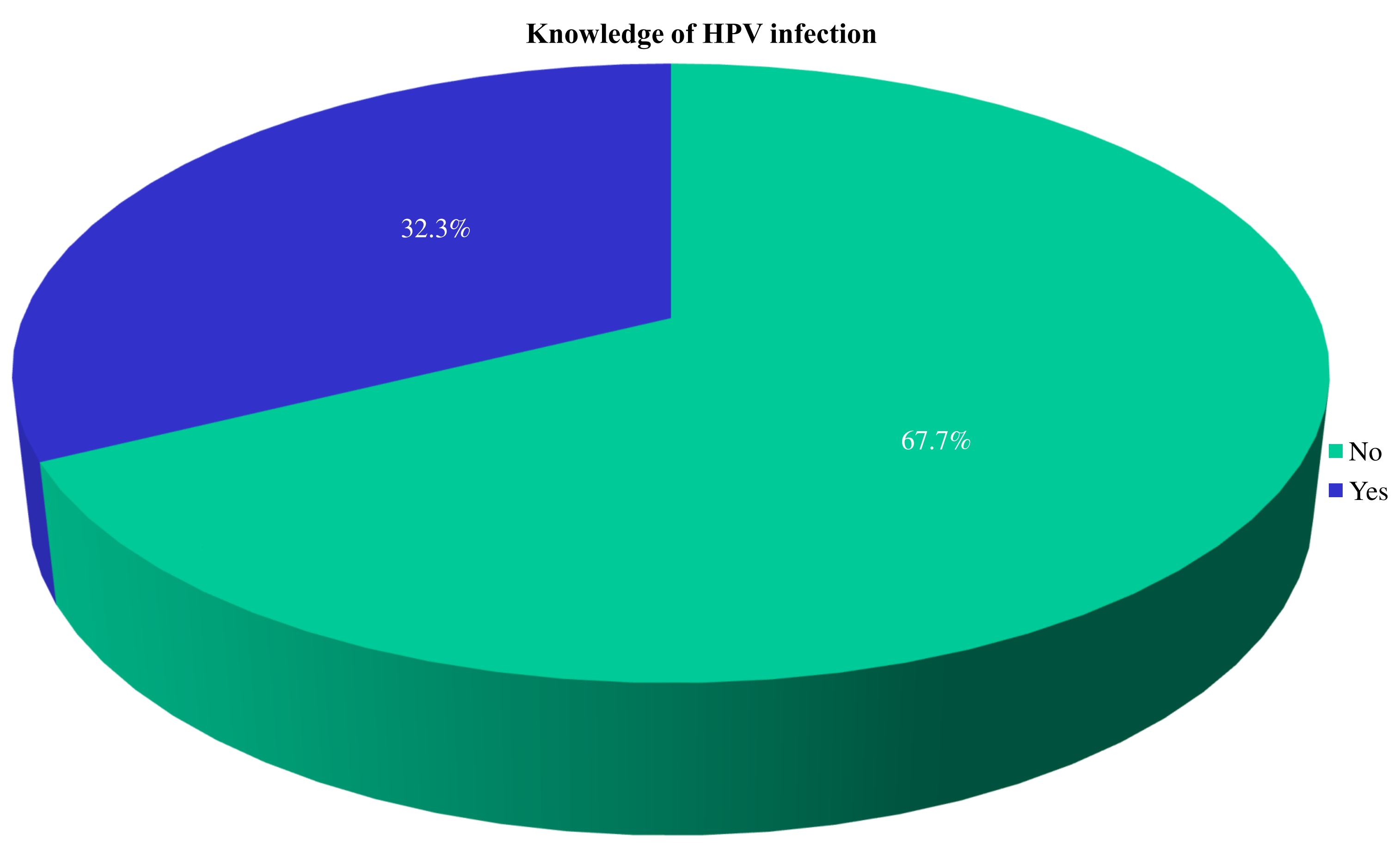

Table 1. Comparison of characteristics across knowledge of HPV infection

\begin{tabular}{|l|l|l|l|l|}
\hline \multicolumn{1}{|l|}{ Characteristics } & Poor & Good & \multirow{2}{*}{ P value } \\
knowledge & Knowledge & \\
\cline { 3 - 4 } Educational & Primary & $24(16.1)$ & $5(7.0)$ & \multirow{2}{*}{$0.001^{*}$} \\
\cline { 2 - 4 } Level & Secondary & $78(52.4)$ & $23(32.4)$ & \\
\cline { 2 - 4 } Age(year) & Tertiary & $47(31.5)$ & $43(60.6)$ & \\
\hline \multirow{2}{*}{ Occupation } & C/servant/stude & $26(17.5)$ & $18(25.4)$ & \multirow{2}{*}{$0.3^{*}$} \\
\hline & nts & $42.5 \pm 7.8$ & $41.8 \pm 7.0$ & \\
\cline { 2 - 4 } & House wife & $10(6.7)$ & $3(4.2)$ & \\
\cline { 2 - 4 } & Trading & $113(75.8)$ & $50(70.4)$ & \\
\hline \# Student t-test, * Pearson's Chi square & \multicolumn{2}{|l}{} \\
\hline
\end{tabular}

CONCLUSION

The awareness and knowledge of HPV infection and HPV vaccine among HIV positive women is very low. This suggests that there is urgent need to put in interventions to increase the knowledge and awareness of this infection among this high risk group. 